\title{
A FEW NOTES ON MY \\ CAREER AS AN ASTROPHYSICIST
}

\author{
P. Swings \\ 23, Avenue Léon Souguenet, 4050 Esneux, Belgium
}

\section{Beginnings}

Nothing in my childhood had prepared me to become an astrophysicist. But in 1922, as a high school prize, I received a wonderful book, Astronomie Populaire by Camille Flammarion. I read this admirable book from the first page to the last, and I decided to do my utmost to become an astrophysicist, forgetting about the plans of my parents (and myself) who were thinking in terms of agriculture.

I was born on September 24, 1906, in Ransart, Belgium, a small industrial town, near Charleroi. My parents were of very modest conditions. I was the best pupil every year in grammar and high school. My teachers were wonderful and I am most grateful to them. At the time I began going to the Charleroi high school in September 1917 Belgium was occupied by the German army. The winter 1917-1918 was very cold and the food rather scarce. Happily I received regularly some bread from the Hoover Foundation (C.R.B., Commission for Relief in Belgium). I used to walk about three miles to high school in the early morning and back home in the late afternoon. My clothing was very mediocre. Despite the material difficulties I was first in my class at Charleroi high school and received the highest government reward every year.

My parents had hardly dared hope that I could go to the University, but my grades in high school were so good that my father decided to continue his sacrifices and to work extra hours. In addition, I also did a great deal of tutoring every Sunday and holiday so that I could start at the University in Liège in 1923.

After obtaining a $\mathrm{PhD}$ in four years-the title of my thesis was "Corrections to the Newton Law and the orbits with moving perihelion" -I was afraid I would be unable to find a job on account of the depression; indeed several of my friends in the University who had obtained PhDs 


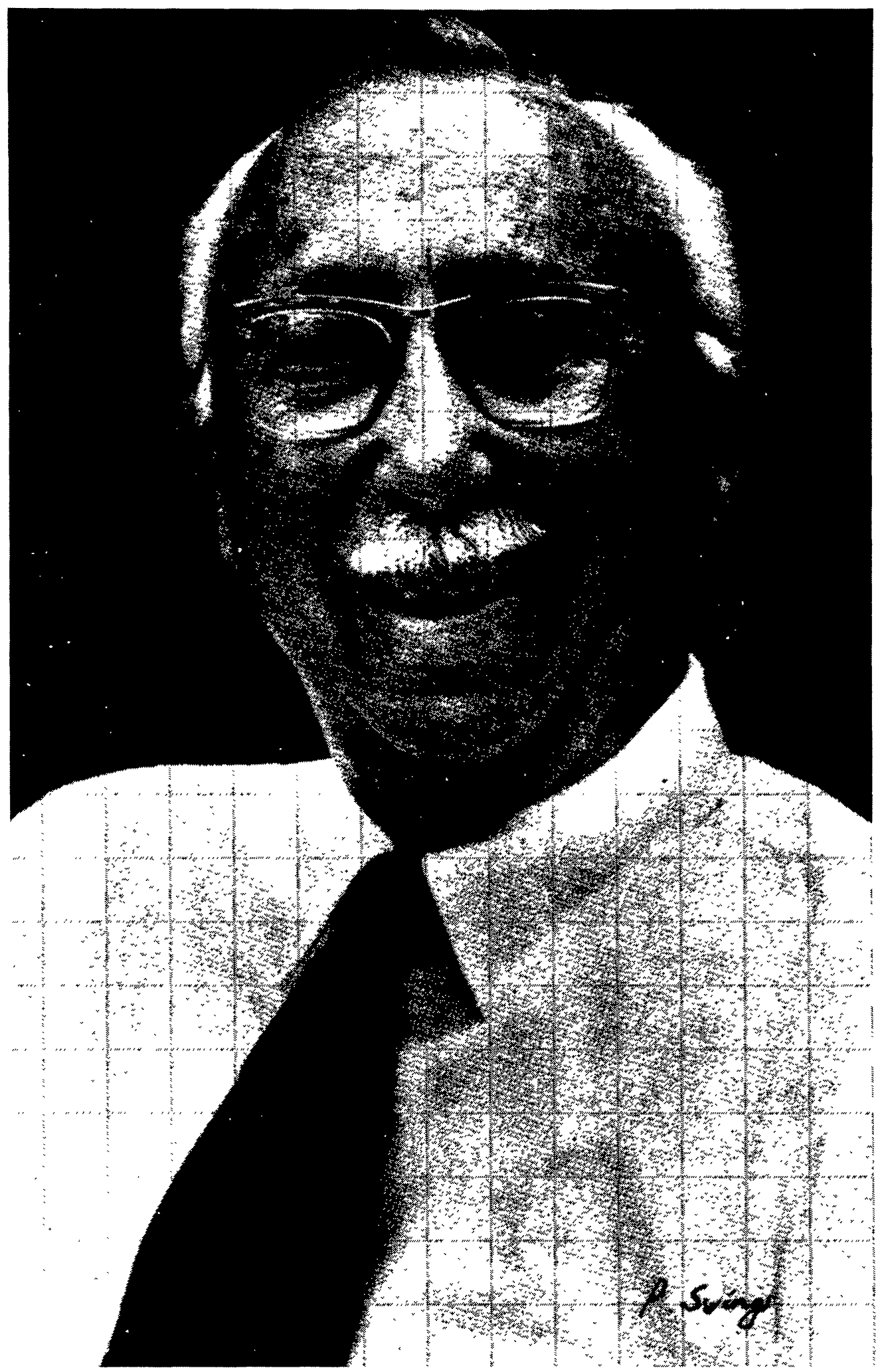

(C) Annual Reviews Inc. - Provided by the NASA Astrophysics Data System 
could not find jobs, even low-paying ones. In order to increase my opportunities, I took a number of practical university courses in survey topography, in mathematics applied to finances and insurance problems, and in insurance legislation. Happily, I got a modest scholarship beginning in 1927.

It was not an easy matter to specialize in astrophysics as there was neither an astrophysicist nor a spectroscopist in the University of Liège. Indeed there was no astrophysicist in any Belgian university! Hence I decided to work by myself in a field, celestial mechanics, which was fairly close to astrophysics. I studied an important part of the four volumes of Tisserand's Celestial Mechanics which I had again received as a prize.

As soon as I had obtained my PhD in Liège (1927) I went to Paris, with a Belgian scholarship, for a one year stay and I took a number of courses in Paris: calculus with Goursat and Picard, celestial mechanics with Andoyer and Chazy, astrophysics with Bruhat, geophysics with Brillouin, optics with Fabry, and spectography with Croze. I also attended occasional lectures by Mme. Curie and P. Langevin. I spent half of my time, however, at the Astrophysical Observatory in Meudon in the solar, cometary, planetary, and stellar services.

The academic year, 1927-1928, was fruitful, but I began to realize that I needed a much more thorough knowledge of spectroscopy if I wanted to do reasonably good work in astrophysics. Thus, I accepted the invitation of Professor Stefan Pieńkowski to go to Warsaw, Poland, for a couple of years to learn spectroscopy. There, in 1931, I obtained another DSc in physics, writing a thesis on the fluorescence of diatomic sulfur. In doing so, I was one of the first Belgian physicists to apply spectroscopy to practical problems, especially metallurgy.

Other practical problems were also being solved. The University of Liège asked me to give a course on applied spectroscopy; I did this in 1933 and published a book in 1935. Professor Charles Fabry, in particular, encouraged me by writing the Preface to this book, the first on applied spectroscopy in the French language.

In 1931 I thus began to devote the major part of my investigations to astronomical spectroscopy. I met the genial Dr. Otto Struve in 1931 at the Yerkes Observatory and I started with him a collaboration that lasted more than 20 years. In addition to my collaboration with Struve I also worked with S. Chandrasekhar, B. Edlén, I. S. Bowen, P. W. Merrill, A. H. Joy, A. S. King, Ch. Fehrenbach, L. Rosenfeld, and J. Kaplan. My astrophysical activity was slowed down from 1943 to 1946 because of a war research assignment in optics in the U.S. Nevertheless, I was able to devote to astrophysics the rare moments of leisure found during this period. 
At first sight, my publications seem to cover a great disparity of topics, since they range from mathematical astronomy to geometrical optics and spectrochemistry. Yet it is clear that my principal interest and, I believe, my main contributions concerned astrophysics. Otto Struve insisted, on several occasions, that my work in physics had prepared me well for the interpretations of astronomical observations.

\section{Importance of the Identifications in Stellar Spectra}

Throughout my career as an astrophysicist, I have been quite unabashedly interested in identifying atoms and molecules in stellar and cometary spectra. For certain astrophysicists, including myself, pure identification work is lots of fun. This point of view, of course, has been criticized for being too descriptive and for entering into too many observational details. However, the contributions of Struve, as well as those of outstanding stellar spectroscopists such as W. S. Adams, P. W. Merrill, A. H. Joy, and R. F. Sanford, have grown out of such studies. Our progress in the theoretical understanding of stellar and other atmospheres could not have gone very far if we had not had identification and detailed description as a sound and solid basis. To take two extreme cases: without the identification of the nebular lines by I. S. Bowen, and his successors, and of the coronal lines by B. Edlén we would not know about forbidden transitions in cosmic bodies. In a more modest case, Bengt Edlén and I devoted two full years of hard steady work to the laboratory analysis of the Fe III spectrum. Forty years later we both still feel that our endeavors paid excellent dividends later on, when it turned out that the forbidden as well as the permitted lines of Fe III explained many features in novae, peculiar bright line stars, and even normal hot stars, including dilution effects in shell stars and other mechanisms affecting the stellar atmospheres.

\section{Unidentified Emission Lines in Of-Stars}

A simple example of how pure identification must be accompanied by studies of intensities and profiles may be found in the work on unidentified emission lines in Of-stars. Two unassigned emission lines were and still are unidentified. Their wavelengths are $\lambda 4485.7 \pm 0.2$ and $\lambda 4503.7 \pm 0.2$ $\AA$. These lines were confirmed by R. J. Wolff (1963). No convincing assignment has been discovered thus far. Dr. Roy H. Garstang and Dr. Michael J. Seaton have computed transition probabilities (even of very complicated spectra, such as the forbidden transitions of Fe II, Fe III, Ni II, etc. . . .) or collisional cross sections. In P Cygni stars strange behaviors are observed in different multiplicities, for example the sextets and quartets in the Fe II multiplets, and the triplets and quintets in $\mathrm{O} \mathrm{I}$. 
Attempts to identify the unexplained lines of the Of-stars have been made without success by several spectroscopists, including B. Edlén, L. Goldberg, R. J. Wolff, A. Underhill, and myself. If these two lines belong to the same element-which is likely-and have one common level, the wavenumber separation between the other two levels should be between 87 and $91 \mathrm{~cm}^{-1}$. We have found no convincing assignment in searching for levels of such separation in C I to IV, N I to V, O I to VI, Si I to IV, but we should not become discouraged!

Individual spectroscopic studies still carry considerable importance. We could not have gotten very far in our understanding of our own milky way and other galaxies if we had not made great progress in individual detailed spectroscopic studies at the observatories of Mt. Wilson, Palomar, McDonald, Lick, Victoria, Kitt Peak, La Silla, Cerro Tololo, and Haute Provence.

\section{Commission 29 (Stellar Spectra) of the International Astronomical Union}

Commission 29 of the International Astronomical Union has, throughout the years, played an important role in stellar spectroscopy. Walter S. Adams was the first chairman of the Commission, organized to discuss stellar spectra. In 1935, when I first attended the I.A.U. meeting at the Paris General Assembly, Commission 29 had only 19 members. Henry Norris Russell, one of the greatest astrophysicists of this century, was then chairman of this small body.

I remember the 1935 meeting, not only because it was the first I attended - and I have attended all the I.A.U. meetings of the Commission since then-but because it was one of the most interesting. There we discussed, and adopted, Beals' classification of Wolf-Rayet stars. Finally, I remember the 1935 meeting because Russell appointed me secretary, and entrusted me with the responsibility of writing the report on the sessions.

Later, in 1948, Otto Struve accepted chairmanship of Commission 29 on condition that I be secretary during his term, and then succeed him, in 1952, as chairman, at which time he would become secretary. Such arrangements were possible then. Members of the Commission who know how close were our collaboration and friendship may have forgotten about this "deal", but they certainly would not be surprised.

The Commission membership has greatly increased, and its responsibilities have grown since those early days. The six eminent stellar spectroscopists who have chaired the Commission since my term, Drs. J. L. Greenstein, L. H. Aller, J. Sahade, Y. Fujita, M. W. Feast, and Mrs. Hack, have done an excellent job adopting standards of comparison for 
the tremendously increased body of data that has accumulated from stellar spectroscopic studies.

\section{Major Research}

In 1975, the 20th Liège International Symposium was devoted to "Astrophysics and Spectroscopy", the fields in which I have primarily worked. There first was a ceremony of hommage in the presence of His Majesty King Baudouin of Belgium who is greatly interested in astronomy and owns several small telescopes. Then, during their introductory speeches, the following personalities stressed the importance of my contributions in various fields of astrophysics: C. Townes (Nobel prizewinner), on intersellar molecules; G. Herzberg (Nobel prizewinner), on cometary spectra and related topics; A. Unsöld, on the history of interrelations between spectroscopic laboratory work and astrophysical problems; $\mathrm{P}$. Conti, on the relation between Of- and WR-stars; L. Aller, on central stars of planetary nebulae; J. Sahade, on symbiotic stars; B. Donn, on problems of cosmic chemistry; G. Münch, on planetary spectroscopy; F. Whipple, on space missions to comets; J. Greenstein, on subluminous stars, post-novae, white dwarfs, and hot subdwarfs. It is very gratifying to see that one's work has had application to such a diversity of problems.

And it is, of course, a compliment to have various phenomena carrying one's name. In my case, this has happened an inordinate number of times. Nevertheless, using the Swings name as a device, I shall try to trace what I consider my major contributions to astrophysics, or at least to outline those areas which have occupied my thought and time throughout my career.

COMETARY PHYSICS The peculiar intensity distribution within the bands had been a puzzle for over half a century. This distribution was interpreted as being due to the presence of the Fraunhofer lines in the exciting solar radiation. The fluorescence mechanism in the comets, called the "Swings effect," is affected by the radial velocity of the comet relative to the Sun. The "grazing comets" show also a very striking "Swings effect." Actually the Swings effect is applicable to all cases of fluorescence excited in astronomical bodies by radiation presenting discrete absorptions or emissions.

PHENOMENA IN THE TWILIGHT AND IN SUNLIT AURORAE The peculiar intensity distribution in the bands of the twilight radiation (especially the $\mathrm{N}_{2}^{+}$spectrum) is interpreted in the same way as in the comets. It is now also called the "Swings effect," for example by Dalgarno and by Vallance Jones; the "Swings effect" is also observed in "sunlit aurorae." 
INTENSE COMETARY EMISSION IN THE NEIGHBOURHOOD OF $\lambda 4050$ This phenomenon had been a puzzle for many decades. On account of my research on this emission Otto Struve suggested that the 4050 group be named the "Swings bands." Many investigators have adopted this recommendation.

The bands near $\lambda 4050$ have been found by G. Herzberg and his associates to be due to the $\mathrm{C}_{3}$ radical. These bands are also observed in the coolest carbon stars and in the phenomena of pyrolysis, solid particles (soot), and hydrocarbons.

THE "SWINGS MECHANISM" IN THE O-STARS WITH EMISSION LINES The excitation mechanism which I discovered in 1948 is explained by the "pumping" by continuum radiation within the multiplets of N III. This mechanism, named the "Swings mechanism" by Mihalas, gives the interpretation of the selectivities among the N III and other emission lines in the Of-stars. It may be presumed that this mechanism will explain other selectivities in hot stars.

THE FIRST FORBIDDEN LINE IN COMETS This phenomenon has been found by J. L. Greenstein and myself to be due to the red doublet of [O I]. This [O I] cometary emission has played an outstanding role, for example in Biermann's cometary investigations.

\section{Conclusion, of Sorts}

I have been fortunate, since obtaining the modest scholarship in 1927, to have found employment as an astrophysicist, and have not had to turn to a career in survey topography or in mathematics as applied to finances and insurance problems. Throughout the years I have taught at the University of Liège, the University of Chicago, and the University of California at Berkeley, and have taken temporary positions in many American universities. I have been a research associate at various institutions, Lick Observatory and Harvard University among them, and have had visiting fellowships in many countries (France, Germany, Poland, USSR, Sweden, Denmark, Norway, U.K., Canada, Eire, Holland, Italy, Switzerland, Turkey, the Vatican). I was Darwin Lecturer at the Royal Astronomical Society, U.K., in 1964.

The graduate courses which I gave to many students in a number of astronomy departments were a source of real satisfaction. My activities with the I.A.U., organizing various symposia, chairing various commissions, and as vice-president (1952-1958) and president (1964-1967) have been rewarding. Perhaps most importantly, my research and collaboration with my colleagues over the years have been most gratifying. 
I and my collaborators continue investigations in a number of areas: cometary physics (including investigations by space vehicles); twilight phenomena and sunlit aurorae, in relation to the profile of the exciting solar spectrum; fluorescence phenomena in hot stars, symbiotic objects, novae, and long period variables; pumping effects in Of-stars; comparative behavior of different multiplicities; far ultraviolet region studies with space vehicles; extension of the observed spectral region in the near infrared; and continuation of the investigations which I started with Otto Struve half a century ago. 